\title{
Browning Potential, Phenolic Composition, and Polyphenoloxidase Activity of Buffer Extracts of Peach and Nectarine Skin Tissue
}

\author{
Guiwen W. Cheng and Carlos H. Crisosto ${ }^{2}$ \\ Department of Pomology, University of California at Davis, Kearney Agricultural Center, Parlier, CA 93648
}

Additional index words. chlorogenic acid, epicatechin, catechin, anthocyanins, skin discoloration, skin browning

\begin{abstract}
The relationship of phenolic composition and polyphenoloxidase activity (PPO, E.C. 1.14.18.1) to browning potential (BP) was studied in buffer extracts of peach [Prunus persica $L$. Batsch) and nectarine [P. persica var. nectarine (L.) Batsch] fruit skin. The BP varied among cultivars with 'Flavorcrest' having the highest value and 'Maycrest' the lowest. On average, over $83 \%$ of the browning measured at the end of the S-hour incubation occurred during the first hour. The total soluble phenolics (TSP), the total anthocyanin (TA), and glutathione content (GLU) varied among cultivars, but were not significantly correlated to the BP. Of the phenolics determined by HPLC, only chlorogenic acid had a significant positive correlation and epicatechin a significant negative correlation with BP by the first hour of incubation. The PPO activity, ranging from 4 to 11 optical density units per gram dry weight per minute among peaches and nectarines, was not significantly correlated with BP. However, no browning was detected if the buffer extract was previously boiled. These results indicated that browning in the buffer extracts of peach and nectarine skin tissue depends on the presence of PPO activity and chlorogenic acid, which are major contributors to enzymatic browning.
\end{abstract}

Fruit browning, as a consequence of bruising, is due to phenolic oxidation (Mathew and Parpia, 1971; Mayer and Harel, 1979; Vamos-Vigyazo, 1981). The destruction of fruit cellular compartmentation allows the phenolic substrates to be accessible to PPOs which catalyze the phenolic oxidation (Mayer and Hare], 1979). The concentration and composition of phenolic compounds and/or activity of PPOs are often the major factors determining tissue browning development and intensity (Matthew and Parpia, 1971; Mayer and Harel, 1979). Furthermore, natural chemicals with antioxidant properties such as thio compounds may also play an important role in fruit browning development (Liyanage et al., 1993; Singleton et al., 1985).

Due to the importance of visual appearance as a produce cosmetic quality parameter, tissue browning has long gained attention from horticultural researchers (Vamos-Vigyazo, 198 1). While numerous studies have used juice, whole fruit and fruit flesh systems, few of them have used skin tissue. Research on fruit skin browning, as a result of friction damage, has only been reported for pears (Mellenthin and Wang, 1974; Ranadive and Haard, 1971). The potential for skin browning on other species including peach and nectarine have not been studied at all.

Peach and nectarine skin discoloration is becoming an important problem for the California stone fruit industry especially on peach cultivars such as 'Flavorcrest', 'Elegant Lady', and 'O'Henry', and nectarine cultivars such as 'Fantasia', 'Royal Giant', and 'Flaming Red'. This skin cosmetic disorder is characterized by the formation of dark brown or black spots and/or light brown spots on the surface of the fruit. Dark brown and black spots commonly called black staining or inking occur as a consequence of abrasion damage to epidermal cells in combination with contaminants (Cheng and Crisosto, 1994; Crisosto et al., 1992, 1993), but light brown spots commonly called skin browning may simply

Received for publication 2 Nov. 1994. Accepted for publication 10 Apr. 1995. This study was funded by a grant from the California Tree Fruit Agreement. We thank Adel A. Kader and Betty Hess for their cooperation. The cost of publishing this paper was defrayed in part by the payment of page charges. Under postal regulations, this paper therefore must be hereby marked advertisement solely to indicate this fact.

${ }^{1}$ Postdoctoral research associate.

${ }^{2}$ Assistant pomologist be a result of epidermal cell abrasion (Crisosto et al., 1993). Although black staining is the main contributor to the incidence of skin discoloration on peach and nectarine fruit, skin browning may also be a potential cause of the disorder.

As this disorder is critical for consumer acceptance, even when the taste of the fruit is not affected, we decided to investigate fruit skin phenolic composition and study its phenolic oxidation to enhance the understanding of stone fruit skin browning. In addition, skin tissue glutathione level was determined to examine its potential effect on browning development.

\section{Materials and Methods}

Plant materials and chemicals. Fruit of 'Maycrest' (MC), 'Flavorcrest' (FC), 'Elegant Lady' (EL), and 'O'Henry' (OH) peaches and 'Mayglo' (MG) and 'Flaming Red' (FR) nectarines were collected from the orchard at the Univ. of California, Kearney Agricultural Center at commercial maturity based on ground color. Among these cultivars, only MG nectarine and MC peach have a low incidence of skin browning as reported commercially under California conditions (Crisosto et al., 1992).

Samples of five fruit were collected from five randomly marked trees per cultivar with four replications. Fruit were carefully harvested, washed with tap water, rinsed with distilled water, and air dried. The skin was peeled off, the flesh tissue scraped off, then frozen immediately in liquid nitrogen, freeze-dried, ground into a powder, and stored at $-40 \mathrm{C}$. All of the chemicals were purchased from Sigma Co.

Browning potential (BP). Skin powder (400 mg) was homogenized under a nitrogen atmosphere in $15 \mathrm{ml}$ of chilled $0.1 \mathrm{M}$ sodium phosphate buffer ( $\mathrm{pH}$ 4.0) (degassed with $\mathrm{NJ}$ with an Ultra-Turrax homogenizer (IKA Labortechnik, Cincinnati, Ohio) for $1 \mathrm{~min}$. The homogenate was centrifuged at $15,000 \times \mathrm{g}$ at $4 \mathrm{C}$ for $10 \mathrm{~min}$. The absorbance at $420 \mathrm{~nm}\left(\mathrm{~A}_{420 \mathrm{~nm}}\right)$ of the warmed-up supernatant (BP extract) was determined using a spectrophotometer (UV160; Shimadzu) at time zero and after incubation for $1 \mathrm{~h}$ and $5 \mathrm{~h}$ in a covered water bath at 30C with slow swirling.

Analysis of phenolics. Soluble phenolics were extracted with methanol (methanol extract) three times and the total soluble 
phenolics (TSP) determined according to Slinkard and Singleton (1977). The total phenolics (TSP) were expressed as gallic acid equivalents (GAE). Total anthocyanins (TA) were estimated as previously described (Cheng and Crisosto, 1994) and expressed as cyanadin-3-glucoside equivalents (CGE):

For high-performance liquid chromatography (HPLC) analysis of phenolics, skin powder (200 mg) was homogenized as above in

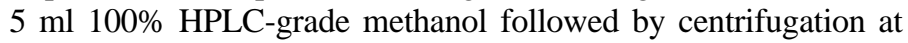
$18,000 \times \mathrm{g}$ for $20 \mathrm{~min}$. Methanol of the supernatant was evaporated with a speed vac concentrator (RC1010; Jouan, Winchester, Va.). The resultant residue was dissolved in $160 \mu \mathrm{l}$ methanol followed by $840 \mu \mathrm{l}$ phosphate buffer $(0.1 \mathrm{M}, \mathrm{pH} 2.8)$, filtered (Millipore, $0.45-\mu \mathrm{m})$, and collected into an auto sampler vial for HPLC analysis according to Gorse 1 et al. (1992). Phenolics were identified and concentration estimated by retention time and co-chromatography of authentic standards.

PPO activity measurements. Skin powder (300 mg) was homogenized as above in $15 \mathrm{ml}$ chilled phosphate buffer $(0.2 \mathrm{M}, \mathrm{pH}$ 6.2). Immediately after homogenization, 5\% PVPP (w/v), $2 \%$ wet Amberlite XAD-4 (w/v), and 2\% Triton X-100 (by volume) were added and vortexed. After $5 \mathrm{~min}$ in an ice bath, the homogenate was filtered through four layers of cheesecloth and centrifuged at $20,000 \times \mathrm{g}$ for $20 \mathrm{~min}$ at $4 \mathrm{C}$. The PPO activity was measured by the change in $\mathrm{A}_{420 \mathrm{~nm}}$ of the assay mixture (30C) that contained $0.5 \mathrm{ml}$ supernatant (enzyme extract), $2.3 \mathrm{ml} 0.1 \mathrm{M}$ phosphate buffer $(\mathrm{pH}$ 6.2), and $0.2 \mathrm{ml} 0.2 \mathrm{M}$ catechol (in buffer) which was added after a 5 min preincubation. The PPO activity is presented as the change in unit of OD at $420 \mathrm{~nm}$ per gram dry weight per minute.

Analysis of glutathione. The glutathione content of $400 \mathrm{mg}$ skin powder was assayed according to Liyanage et al. (1993) after extraction with $15 \mathrm{ml} 0.5 \%$ perchloric acid (v/v).

Statistical analysis. The Statistical Analysis System (SAS) for the personal computer program (SAS Inst., 1988) was used for the ANOVA, LSD means separation, single, Pearson and stepwise regression analyses.

\section{Results}

Browning potential. Skin browning response varied among different fruit skin extract samples. FC presented the highest and MC the lowest BP among the tested cultivars by the end of the first and fifth hour of incubation. There were no significant differences in BP between skin extracts of MG, EL, OH, and FR by the end of the first and fifth hour of incubation (Table 1). The absorbance at zero time ranged from 0.404 to 0.598 OD among all of the samples and did not correlate with the BP measured after the first or fifth hour of incubation (data not shown). Most of the browning was completed during the first hour of incubation. The percentage of $\mathrm{BP}$ which occurred during the first hour of incubation ranged from $74 \%$ (MC) to $97 \%$ (MG), averaging $83 \%$ for all cultivars (Fig. 1). Additional experiments with skin samples of FC and FR showed that of the browning occurring during the first hour, up to $75 \%$ occurred during the initial 30 minutes. Browning was not observed in any of the buffer solutions containing the dried phenolic residue of skin methanol extracts or in the boiled skin buffer extracts (data not shown).

Total soluble phenolics and total anthocyanin content. Differences in total soluble phenolics content varied from 5.5 to $8.4 \mathrm{mg}$ GAE/g dry weight (Table 1). The skin tissue of MC, FC, and EL had the highest, while that of $\mathrm{MG}$ and $\mathrm{OH}$ the lowest level of total soluble phenolics. The content of anthocyanins averaged $1 \mathrm{mg}$ $\mathrm{CGE} / \mathrm{g}$ dry weight in the skin tissue of the peach and nectarine fruits examined (Table 1). Neither TSP nor TA showed significant correlation with the BP (Table 2).

Of the major peaks commonly shown on the HPLC chromatograms, three were identified as chlorogenic acid, (+)-catechin and (-)-epicatechin. There were three other unidentifiable peaks of considerable peak size (A, B, C) with retention times of $8.72 \mathrm{~min}$, $16.24 \mathrm{~min} 17.41 \mathrm{~min}$, respectively. In all of the cultivars tested, the concentrations of (-)-epicatechin and chlorogenic acid were higher than that of (+)-catechin (Table 1). FC presented the lowest (-)epicatechin and the highest chlorogenic acid content among all of the cultivars tested.

PPO activity. PPO activity in the enzyme extracts was lowest in the early cultivars such as MG, MC, and moderate in mid season cultivars such as FC, EL, and $\mathrm{OH}$ and significantly higher in the late FR cultivar (Table 1). However, when the enzyme extracts and the BP extracts were boiled, activity of PPO was not detectable.

Analysis of glutathione. The glutathione content was higher in the two early cultivars (MC and MG) than for the mid and late season cultivars (Table 1).

Chlorogenic acid and (-)-epicatechin content were significantly correlated with BP for the first hour, but not the following four hours of incubation (Table 2). Pearson's correlation analysis indicated that (-)epicatechin content had a negative correlation to $\mathrm{BP}(r=-0.83, P=0.040)$ whereas all of the other phenolics tested had a positive correlation to BP. Peak A that eluted after gallic acid but before (+)-catechin showed a significant positive correlation with the BP in the last four hours, but not in the first hour of incubation. The concentrations of (+)- catechin, TSP, TA, glutathione and PPO activities were not correlated to the BP for the first hour and the following four hours of incubation (Table 2).

When stepwise regression analysis was performed, addition of other phenolics, glutathione, and/or PPO activity, after chloro-

Table 1. Skin browning potential $\left({ }_{A 420}\right)$, phenolic levels, PPO activity, and glutathione level of different peach/nectarine cultivars.

\begin{tabular}{|c|c|c|c|c|c|c|c|c|c|}
\hline \multirow[b]{3}{*}{ Cultivars } & \multicolumn{2}{|c|}{ Browning potential } & \multirow{3}{*}{$\begin{array}{c}\text { Total soluble } \\
\text { phenolics } \\
\left.\text { (mg GAE/g DW }{ }^{z}\right)\end{array}$} & \multirow{3}{*}{$\begin{array}{c}\text { Total } \\
\text { anthocyanins } \\
(\mathrm{mg} \mathrm{CGE} / \mathrm{g} \mathrm{DW})\end{array}$} & \multirow{2}{*}{$\begin{array}{c}\text { Chlorogenic } \\
\text { acid } \\
\end{array}$} & \multirow[b]{2}{*}{ Catechin } & \multirow[b]{2}{*}{ Epicatechin } & \multirow[b]{2}{*}{$\mathrm{PPO}$} & \multirow[b]{2}{*}{ Gluthatione } \\
\hline & $0-1$ st & 2 nd- -5 th & & & & & & & \\
\hline & $\mathrm{h}$ & $\mathrm{h}$ & & & & $\left(\mathrm{mg} \cdot \mathrm{g}^{-1} \mathrm{DW}\right)$ & & $(\Delta \mathrm{OD} / \mathrm{g} \mathrm{DW}$ & $\left(\mu \mathrm{g} \cdot \mathrm{g}^{-1} \mathrm{DW}\right)$ \\
\hline Maycrest & 0.134 & 0.049 & 7.89 & 1.26 & 1.42 & 0.66 & 4.17 & 4.5 & 135.4 \\
\hline Mayglo & 0.163 & 0.006 & 5.50 & 1.24 & 1.16 & 0.67 & 4.33 & 3.7 & 124.3 \\
\hline Flavorcrest & 0.236 & 0.048 & 8.00 & 0.88 & 2.43 & 1.30 & 2.74 & 6.6 & 85.3 \\
\hline Elegant Lady & 0.158 & 0.030 & 8.43 & 1.00 & 1.28 & 0.88 & 4.59 & 5.6 & 55.2 \\
\hline O'Henry & 0.179 & 0.057 & 6.65 & 1.00 & 1.62 & 1.46 & 4.06 & 6.6 & 89.0 \\
\hline Flaming Red & 0.160 & 0.032 & 7.48 & 0.98 & 0.93 & 0.98 & 3.69 & 11.2 & $77.9 \div$ \\
\hline$P$-value & 0.001 & 0.007 & 0.0009 & 0.001 & 0.0001 & 0.0001 & 0.044 & 0.008 & 0.001 \\
\hline LSD 0.05 & 0.037 & 0.024 & 1.27 & 0.18 & 0.39 & 0.19 & 1.14 & 3.5 & 22.5 \\
\hline
\end{tabular}

${ }^{\bar{D} \mathrm{DW}}=$ dry weight. 


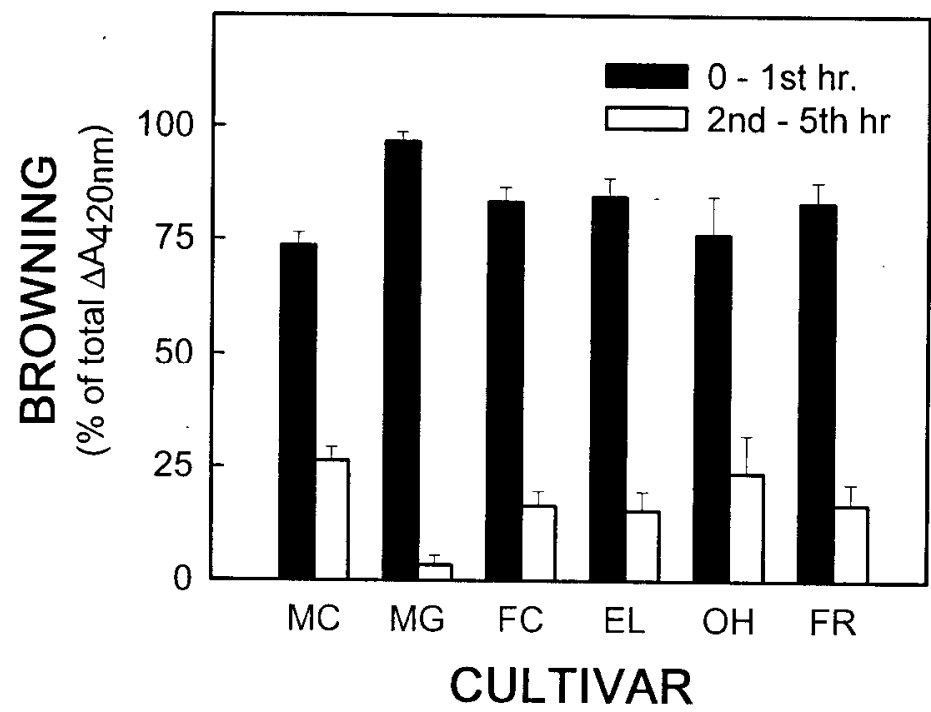

Fig.1. The percentage of the total browning potential during the first ( $0-1 \mathrm{st} h)$ and the following four hour periods (2nd-5th h) of incubation in buffer extracts of freeze-dried peach and nectarine skin fruit tissues at 30C. MC = 'May Crest', MG $=$ 'Mayglo', FC = 'Flavorcrest', EL = 'Elegant Lady'. $\mathrm{OH}=$ 'O' Henry', and FR $=$ 'Flaming Red'. Vertical bars represent \pm SD.

genie acid did not alter the significance of the regression model (data not shown). Additional correlation analysis demonstrated that TSP also was not related with chlorogenic acid or other phenolics (data not shown).

\section{Discussion}

Our work demonstrated that browning in the fruit skin buffer extracts was an enzymatic reaction catalyzed by PPO because browning and PPO activity occurred in the BP extracts but not in boiled BP extracts. Our results are in agreement with other studies on fresh fruits and other plant materials. Enzymatic oxidation of phenolics via PPOs accounts for most plant tissue browning, particularly that which occurs very rapidly (Mathew and Parpia, 1971; Mayer and Harel, 1979; Vamos-Vigyazo, 198 1). Our work also indicated that nonenzymatic oxidation was limited in the BP extracts, if it occurred at all.

The high correlation between BP and the chlorogenic acid level implies an important role for this o-diphenol in skin browning. More browning occurs in frozen and thawed peach juice that has abundant chlorogenic acid and other o-diphenols, but less in peaches that have small amounts of chlorogenic acid and negligible other o-diphenols (Bureau et al., 1977). A positive correlation between BP and o-diphenol content has been reported in flesh and whole fruit tissues of several other fruits as well (Bureau et al., 1977; Hare1 et al., 1966; Ranadive and Haard, 197 1; VamosVigyazo and Nadudvari-Markus, 1982). FC peach had the lowest (-)-epicatechin and the highest chlorogenic acid content and BP which coincided with the high incidence of skin browning incidence observed during commercial operations and in our laboratory tests, respectively (Crisosto et al., 1992, 1993). MC had the lowest chlorogenic acid and BP which also agrees with our laboratory tests and industry observations.

The association of chlorogenic acid content with the BP in the first hour but not the following four hour incubation suggests that chlorogenic acid oxidation proceeded quickly. Rapid browning has also been observed in other fruit tissues (Guadagni et al., 1949; Vamos-Vigyazo and Nadudvari-Markus, 1983). Oxidation of chlo-
Table 2. Correlations $\left(r^{2}\right)$ between browning potential $\left(\mathrm{A}_{420}\right)$ and total soluble phenolics, individual phenolics, glutathione, total anthocyanin content, and polyphenoloxidase activity (PPO) in buffer extracts of peach and nectarine fruit skin tissue.

\begin{tabular}{lcc} 
& \multicolumn{2}{c}{ Browning potential } \\
\cline { 2 - 3 } & $0-1 \mathrm{st} h$ & $2 \mathrm{nd}-5$ th $\mathrm{h}$ \\
\hline Chlorogenic acid & $0.71_{(0.036)}$ & NS \\
Catechin & NS & NS \\
Total soluble phenolics & NS & NS \\
Total anthocyanins & NS & NS \\
PPO & NS & NS \\
Epicatechin & $0.69_{(0.040)}$ & NS \\
Peak A & NS & $0.67_{(0.046)}$ \\
Peak B & NS & NS \\
Peak C & NS & NS \\
Glutathione & NS & NS \\
\hline
\end{tabular}

${ }^{2}$ Correlation coefficients and $P$ values (in subscripts).

rogenic acid is known to happen much faster than other fruit phenolics such as (+)-catechin and proanthocyanidins (Oleszek et al., 1989). Our data indicated that skin browning occurring between the second and fifth hours was related to peak A. Based on the retention time and the absence of absorbance at $320 \mathrm{~nm}$ and 360 $\mathrm{nm}$, we suggest that peak A is a type of hydroxyl substituted benzoic acid. It has been reported that PPO isolated from peach fruits shows low to moderate activity on some hydroxybenzoic acid(s) phenolic derivatives (Flurkey and Jen, 1980; Jen and Kahler, 1974). This may explain the correlation of peak A with the $\mathrm{BP}$ in the last four hours of incubation.

Variability in color intensity developed by different phenolics in the calorimetry used for TSP estimation (Coseteng and Lee, 1987) may offer an explanation for the absence of a relationship between TSP and BP. The lack of correlation between TSP and chlorogenic acid favors such an interpretation.

The absence of a significant correlation between PPO activity and BP indicates that the PPO was not a limiting factor in the enzymatic browning. PPO activity was adequate in carrying out the phenolic oxidation under our experimental conditions. Both presence and absence of PPO activity dependency in fruit browning have been reported among grape cultivars (Romeyer et al., 1986; Sapis et al., 1983) and apples (Coseteng and Lee, 1987; Ingle and Hyde, 1968; Vamos-Vigyazo et al., 1977).

The protective role of glutathione in browning (Liyanage et al., 1993; Singleton et al., 1985) seems to be limited since the tissue content was low. Further experiments are needed to quantify the glutathione, (-)-epicatechin and ascorbic acid contribution to skin browning incidence.

In summary, BP of buffer extracts of peach and nectarine fruit skin tissue during the first hour of incubation was positively correlated with the content of skin chlorogenic acid, suggesting that availability of chlorogenic acid is a limiting factor in the enzyme-mediated process.

\section{Literature Cited}

Bureau, D., J.J. Macheix, and M.A. Rouet-Mayer. 1977. Relations entre la tenneur en o-diphnols, l'activite polyphnoloxydasique et l'aptitude au brunissement de quelques varietes de peches. Lebensm. Wiss. Technol. 10:211-216.

Cheng, G.W. and C.H. Crisosto. 1994. Development of dark discoloration on peach and nectarine (Prunus Persica. L. Batsch) fruit in response to exogenous contamination. J. Amer. Hort. Sci. 119:529-533.

Coseteng, M.Y. and C.Y. Lee. 1987. Changes in apple polyphenoloxidase 
and polyphenol concentrations in relation to degree of browning. J. Food. Sci. 52:985-989.

Crisosto, C.H., G. Cheng, K. R. Day, D. Gamer, H. Hansen, E. Hose, K. Taylor, C. Boynton, and B. Beede. 1992. Skin discoloration in peach and nectarine fruit. California Fruit Tree Agreement. Annu. Rpt. Res. Projects.

Crisosto, C.H., R.S. Johnson, J. Luza, and K. Day. 1993. Incidence of physical damage on peach and nectarine skin discoloration development: anatomical studies. J. Amer. Hort. Sci. 118:796-800.

Flurkey, W.H. and J.J. Jen. 1980. Purification of peach polyphenol oxidase in the presence of added protease inhibitors. J. Food Biochem. 4:29-41.

Gorsel, H., C. Li, E.L. Kerbel, M. Smiths, and A.A. Kader. 1992. Compositional characterization of prune juice. J. Agr. Food Chem. 40:784-789.

Guadagni, D.G., D.G. Sorber, and J.S. Wilbur. 1949. Enzymatic oxidation of phenolic compounds in frozen peaches. Food Technol. 3:359-364.

Harel, E., A.M. Mayer, and Y. Shain. 1966. Catechol oxidizes, endogenous substrates and browning in developing apples. J. Sci. Food Agr. 17:389-391.

Ingle, M. and J.E. Hyde. 1968. The effect of bruising on discoloration and concentration of phenolic compounds in apple tissue. J. Amer. Hort. Sci. 93:738-745.

Jen, J.J. and K.R. Kahler. 1974. Characterization of polyphenol oxidase in peaches grown in the southeast. HortScience 9590-591.

Liyanage, C., D.A. Luvisi, and D.O. Adams. 1993. The glutathione content of grape berries is reduced by fumigation with methyl bromide or methyl iodide. Amer. J. Enol. Viticult. 44:8-12.

Mathew, A.G. and H.A.B. Parpia. 1971. Food browning as a polyphenol reaction. Adv. Food Res. 19:75-145.

Mayer, A.M. and E. Harel. 1979. Polyphenol oxidases in plants. Phytochemistry 18:193-215.

Mellenthin, W.M. and C.Y. Wang. 1974. Friction discoloration of 'd' Anjou' pear in relation to fruit size, maturity, storage and polyphenoloxidase activities. HortScience 9:592-593.

Oleszek, W., Y.L. Chang, A.W. Jaworski, and K.R. Price. 1989. Apple phenolics and their contribution to enzymatic browning reactions. Acta Societatis Botanicorum Poloniae 58:273-283.

Ranadive, A.S. and N.F. Haard. 1971. Changes in polyphenolics on ripening of selected pear varieties. J. Sci. Food Agr. 22:8689.

Romeyer, F.M., J.J. Macheix, and J.C. Sapis. 1986. Changes and importance of oligomeric procyanidins during maturation of grape seeds. Phytochemistry 25:219-221.

Sapis, J.C., J.J. Macheix, and R.E. Cordonnier. 1983. The browning capacity of grapes. II. Browning potential and polyphenol oxidase activities in different mature grape varieties. Amer. J. Enol. Viticult. 34: $157-162$.

SAS Institute. 1988. SAS/STAT user's guide. release 6.03. SAS Inst., Cary, N.C.

Singleton, V.L., M. Salgues, J. Zaya, and E. Trousdale. 1985. Caftaric acid disappearance and conversion to products of enzymic oxidation in grape must and wine. Amer. J. Enol. Viticult. 36:50-56.

Slinkard, K. and V.L. Singleton. 1977. Total phenol analysis: Automation and comparison with manual methods. Amer. J. Enol. Viticult. 28:4955.

Vamos-Vigyazo, L. 1981. Polyphenol oxidase and peroxidase in fruits and vegetables. CRC Crit. Rev. Food Sci. Nutr. 15:49-127.

Vamos-Vigyazo, L., K. Mihalyi, I. Gajzago, and V. Nadudvari-Markus. 1977. The role of enzyme-substrate ratio in the enzymatic browning of fruit tissue homogenates. Acta Alimentaria 6:379-388.

Vamos-Vigyazo, L. and V. Nadudvari-Markus. 1982. Enzymatic browning, polyphenol oxidase and peroxidase in pear cultivars. Acta Alimentaria 11:157-168.

Vamos-Vigyazo, L.and V.Nadudvari-Markus. 1983. Inactivation of polyphenol oxidase and depletion of o-dihydroxyphenol content during the enzymatic browning reaction of fruit tissues. Acta Alimentaria 12: 1-9. 